\title{
Increasing efficiency of process of stem feed grinding by working tool of hammer-segment type
}

\author{
Vladimir Frolov ${ }^{1 *}$, Natalya Sarbatova ${ }^{1}$, Vladimir Kuznetsov ${ }^{1}$, and Nadezhda Strigunova ${ }^{1}$ \\ ${ }^{1}$ Kuban State Agrarian University, Faculty of Mehanization, , 13 Kalinina St. 350004Krasnodar
}

\begin{abstract}
The achievements of dairy breeding in the Kuban have become possible thanks to the full balanced feeding of animals. The main condition for the rational use of feed, increasing its efficiency is proper preparation for feeding, the use of high-tech equipment selected in the production and production lines.
\end{abstract}

\section{Introduction}

Stem feeds, which make up $40 \%$ of the diet, previously prepared, are eaten by animals 40 $60 \%$ better, fodder losses are minimal. The process of grinding the stem fodder allows to obtain ground fodder particles having a large surface, which makes it possible for the animal to save energy during the process of consuming the fodder. Feed prepared in the grinder is rationally dosed, mixed and fed to feeders or to the feed table. The need for feed grinders in the Kuban is high - use in private and farm farms, during the reconstruction and modernization of farms. The dynamic development of the livestock industry requires hightech equipment that consumes little energy, mobile, quickly customizable and safe to work. These requirements are met by a stem fodder grinder with a hammer-segment type working member (patent No. 2639326 Fodder-grinder) [1-3].

\section{Materials and methods}

To reduce the energy consumption of the process of grinding and increase the fodder quality in the fodder-grinder (Figure 1) comprising a housing 1 in the form of a hopper 2 and a discharge element 3 with a rotating disc 4 with working grinding elements 5; installed in annular rows and an anti-cutting member, according to the invention grinding members are made in the form of a cylindrical sleeve 6 with a rod 7; in the upper part of which a toothed cutting element 8 is rigidly installed at an angle of $30^{\circ}-45^{\circ}$ to the longitudinal axis of the cylindrical sleeve 6 ; and the cutter 9 is made in the form of a spring-loaded deck with cutter segments 10; The latter is secured by one side by hinge 11 on side wall of housing 1 by means of spring-loaded pin 12 to vary clearance between toothed cutting segments and anticutting segments to vary weighted average length of cut material [4-7].

\footnotetext{
* Corresponding author: Frolov_v65@mail.ru
} 

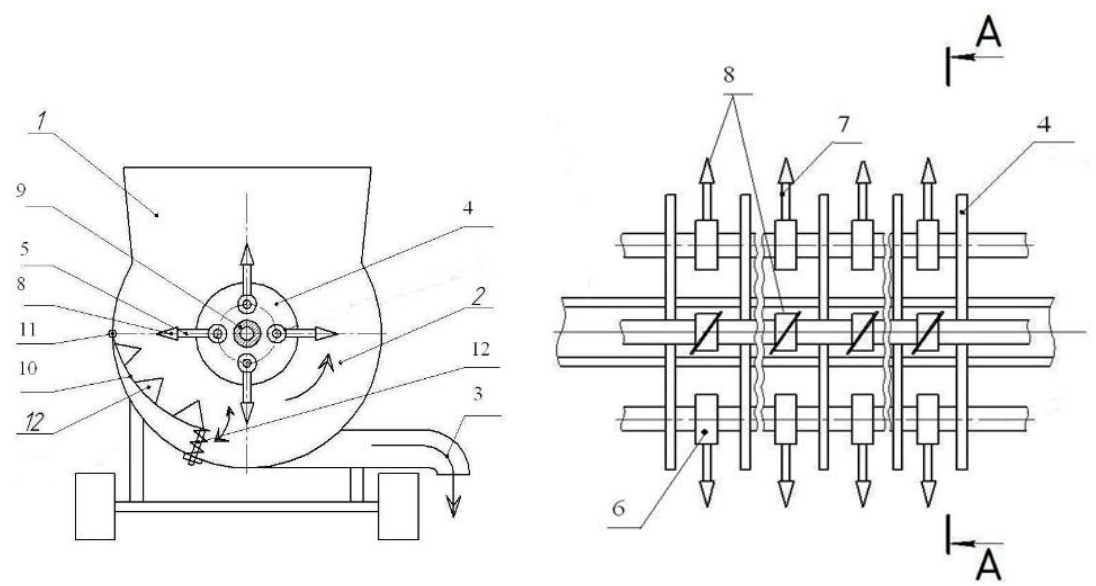

Fig. 1. Fodder-grinder.

Feed mass input into grinding drum with hammer-segment working member is determined by parameters of fed material and physical and mechanical properties of feed. The increased humidity of the stem feed increases the energy consumption of the process by $30 \%$ and reduces the productivity of the grinder.

\section{Results and discussions}

During the study, analytical dependencies of the support division of the fracture rate of the material were obtained, which imply the determination of the total energy obtained by the material during impact

$$
\mathrm{S}=\int_{0}^{\Delta \mathrm{t}} \mathrm{Fdt}=\mathrm{F} \Delta \mathrm{t}
$$

Applying the theorem on the amount of motion of a material point we get:

$$
\mathrm{mU}-\mathrm{mV}=\mathrm{F} \Delta \mathrm{t}
$$

where $\mathrm{V}$ - point speed before impact, $\mathrm{m} / \mathrm{s} ; \mathrm{U}$ - point speed after impact, $\mathrm{m} / \mathrm{s} ; \Delta \mathrm{t}$ - duration of impact, s; F - average (during the impact period) instantaneous force, $\mathrm{kg} * \mathrm{~m} / \mathrm{s} 2$.

If $\mathrm{V}=0$ is accepted, then

$$
\mathrm{U}=\frac{\mathrm{F} \Delta \mathrm{t}}{\mathrm{m}}
$$

The total energy obtained by the material upon impact is determined by the formula:

$$
\mathrm{E}=\mathrm{E}_{3}+\mathrm{E}_{4}=\frac{\mathrm{mv}^{2}}{2}(1-\mu)^{2}\left(1+\mathrm{k}^{2}\right)+\frac{\mathrm{mv}^{2}}{2}\left[(\mathrm{k}-\mathrm{k} \mu+1)^{2}-\mu^{2}\right] .
$$

Or, after simplifications, the form is obtained:

$$
\mathrm{E}=\mathrm{mV}^{2}(1+\mathrm{k})(1-\mu)
$$

$\mu$ is a coefficient equal to the ratio of the speed of the material layer to the circumferential speed of the working elements.

If you ignore the speed of movement of the layer by taking $\mu=0$, then the expression (4) takes the form: 


$$
\mathrm{E}=\mathrm{mV}^{2}(1+\mathrm{k})
$$

$\mathrm{m}$ - weight, $\mathrm{kg} ; \mathrm{V}$ - speed, $\mathrm{m} / \mathrm{s} ; \mathrm{k}$ is the elastic coefficient of the material.

That is, the energy produced by the material on impact is greater, the higher the elastic properties of the material and the smaller the $\mu$.

The following formulas are used to determine the velocity of the particles on the inner surface of the grinding chamber:

$$
\left\{\begin{array}{l}
\mathrm{m} \frac{\mathrm{d}^{2} \mathrm{x}}{\mathrm{dt}^{2}}=X \\
\mathrm{~m} \frac{\mathrm{d}^{2} \mathrm{y}}{\mathrm{dt}^{2}}=Y
\end{array}\right.
$$

where $\mathrm{X}$ and $\mathrm{Y}$ are projections on the coordinate axes of all forces applied to the particle.

Since $\frac{d^{2} x}{d t^{2}}=\frac{d V_{x}}{d t}, Y=0$ and $V_{x}=V_{m}$, we obtain the differential equation as:

$$
\mathrm{m} \frac{\mathrm{d} \mathrm{v}_{\mathrm{m}}}{\mathrm{dt}}=\mathrm{X} \text {. }
$$

At the same time

$$
\mathrm{X}=\mathrm{F}_{\mathrm{тр}}+\mathrm{F}_{\mathrm{a}},
$$

where $\mathrm{F}_{t r}$ - friction force; because $\mathrm{G}=0$, then $\mathrm{N}=\mathrm{Q}$ and

$$
\mathrm{F}_{t r}=\mathrm{Qf}=\frac{\mathrm{mV}^{2} \mathrm{~m}}{\mathrm{R}_{\mathrm{k}}} \mathrm{f},
$$

$\mathrm{F}_{\mathrm{a}}$ - aerodynamic drag force, which is determined by formula

$$
\mathrm{F}_{\mathrm{a}}=\mathrm{cF} \frac{\mathrm{v}_{\mathrm{M}}^{2}}{2 \mathrm{~g}} \gamma_{\beta}
$$

where $\mathrm{Q}$ - centrifugal force, $\mathrm{kg} * \mathrm{~m} / \mathrm{s} 2 ; \mathrm{F}$ - the projection of the particle onto a plane perpendicular to the direction of its movement; $\gamma_{\beta}$ - specific gravity of air, $\mathrm{m}^{3} / \mathrm{kg}$; $\mathrm{f}$ - friction coefficient; $\mathrm{V}_{\mathrm{m}}$ - particle speed, $\mathrm{m} / \mathrm{s}$; $\mathrm{c}$ - a factor depending on the shape of the particle and is a function of the Reynolds number $(\mathrm{Re})$.

After the transformations, differential equation (7) takes the form:

$$
-\mathrm{m} \frac{\mathrm{dV} \mathrm{m}}{\mathrm{dt}}=\frac{\mathrm{fm} V_{\mathrm{m}}^{2}}{\mathrm{R}_{\mathrm{k}}}+\mathrm{cF} \frac{\mathrm{V}_{\mathrm{m}}^{2}}{2 \mathrm{~g}} \gamma_{\beta}
$$

or

$$
-\frac{d V_{m}}{d t}=(a+b) V_{m}^{2}
$$

where

$$
\mathrm{a}=\frac{\mathrm{f}}{\mathrm{R}_{\mathrm{k}}}, \mathrm{b}=\frac{\mathrm{cF} \gamma_{\beta}}{2 \mathrm{gm}}
$$

By dividing the variables and integrating we get:

$$
-\int_{V_{0}}^{V_{m}} \frac{d V_{m}}{V_{m}^{2}}=(a+b) \int_{0}^{t} a t
$$




$$
\frac{1}{\mathrm{v}_{\mathrm{m}}}=\frac{1}{\mathrm{v}_{0}}+(\mathrm{a}+\mathrm{b}) \mathrm{t}
$$

from where

$$
\mathrm{V}_{\mathrm{m}}=\frac{\mathrm{V}_{0}}{1+(\mathrm{a}+\mathrm{b}) \mathrm{t}_{0}}
$$

Or finally

$$
\mathrm{V}_{\mathrm{m}}=\frac{\mathrm{V}_{0}}{1+\left(\frac{\mathrm{f}}{\mathrm{R}_{\mathrm{k}}}+\frac{\mathrm{CF} \gamma_{\beta}}{2 \mathrm{gm}}\right) \mathrm{tV}}
$$

$\mathrm{V}_{0}$ - initial speed, $\mathrm{m} / \mathrm{s} ; \mathrm{R}_{\mathrm{k}}$ - crushing chamber radius, $\mathrm{m}$; $\mathrm{f}$ is friction coefficient; $\gamma_{\beta}$ - specific gravity of air, $\mathrm{m}^{3} / \mathrm{kg}$; $\mathrm{c}$ - a particle shape-dependent coefficient which is a function of the Reynolds number (Re); F - projection of the particle onto a plane perpendicular to the direction of its movement [8-9].

After analyzing the obtained dependencies, it can be seen that the energy intensity of the process with a decrease in the radius of the drum $R_{p}$ will decrease along with an increase in quality indicators.

The dependence analysis (15) showed that the velocity of the material particles directly depends on the diameter of the grinding chamber. The smaller the diameter of the grinding chamber, the thinner the grinding modulus of the material, and the more efficient and better the working process.

During the study, factors that significantly influence the grinding process, as well as their varying levels, were determined. The main factors are: $\mathrm{X}_{1}$ - circumferential speed of hammers, $\mathrm{m} / \mathrm{s} ; \mathrm{X}_{2}$ - moisture content of the material, \%; $\mathrm{X}_{3}$ - diameter of holes of separating screen, $\mathrm{mm} ; \mathrm{X}_{4}$ - number of rows of hammers [10].

The criteria for optimizing the grinding process are: $\mathrm{Y}_{1}$ - grinding modulus, $\mathrm{mm} ; \mathrm{Y}_{2}$ energy intensity $\mathrm{kW} \mathrm{s} / \mathrm{kg}$.

In the process of research, regression equations for the above studies are obtained:

- in coded form:

$$
\begin{gathered}
\mathrm{Y}_{1}=1,5273-0,8167 \mathrm{X}_{1}+0,11 \mathrm{X}_{2}+0,5 \mathrm{X}_{3}-0,2765 \mathrm{X}_{4}+0,008 \mathrm{X}_{1}^{2}-0,001 \mathrm{X}_{2}^{2}-0,005 \mathrm{X}_{3}^{2}-0,003 \mathrm{X}_{4}{ }^{2} \\
\mathrm{Y}_{2}=0,4551-0,1842 \mathrm{X}_{1}-0,04 \mathrm{X}_{2}-0,0575 \mathrm{X}_{3}+0,062 \mathrm{X}_{4}+0,002 \mathrm{X}_{1}^{2}+0,0004 \mathrm{X}_{2}{ }^{2}+0,0006 \mathrm{X}_{3}{ }^{2}-0,0006 \mathrm{X}_{4}{ }^{2}(17
\end{gathered}
$$

- in decoded form:

$$
\begin{array}{r}
\mathrm{Y}_{1}=-10,07806667-0,02 \mathrm{X}_{1}+3,4365 \mathrm{X}_{2}+0,073 \mathrm{X}_{3}-0,2 \mathrm{X}_{4}+0,0015 \mathrm{X}_{1} \mathrm{X}_{2}-0,0001 \mathrm{X}_{1} \mathrm{X}_{3}+0,0001 \mathrm{X}_{1} \mathrm{X}_{4}+ \\
0,009 \mathrm{X}_{2} \mathrm{X}_{3}+0,0045 \mathrm{X}_{2} \mathrm{X}_{4}-0,001 \mathrm{X}_{3} \mathrm{X}_{4}-0,12 \mathrm{X}_{2}{ }^{2}-0,0024 \mathrm{X}_{3}{ }^{2}+0,0137 \mathrm{X}_{4}{ }^{2}(18) \\
\mathrm{Y}_{2}=5,466-0,0035 \mathrm{X}_{1}-1,29 \mathrm{X}_{2}-0,123 \mathrm{X}_{3}-0,038 \mathrm{X}_{4}-0,0026 \mathrm{X}_{1} \mathrm{X}_{2}-0,0001 \mathrm{X}_{1} \mathrm{X}_{4}-0,0034 \mathrm{X}_{2} \mathrm{X}_{3}+ \\
0,0025 \mathrm{X}_{2} \mathrm{X}_{4}-0,0003 \mathrm{X}_{3} \mathrm{X}_{4}+0,05 \mathrm{X}_{2}^{2}+0,011 \mathrm{X}_{3}^{2}+0,0058 \mathrm{X}_{4}{ }^{2}
\end{array}
$$

Based on regression equations, response surfaces for the grinding modulus and energy intensity are constructed (Fig. 2). 

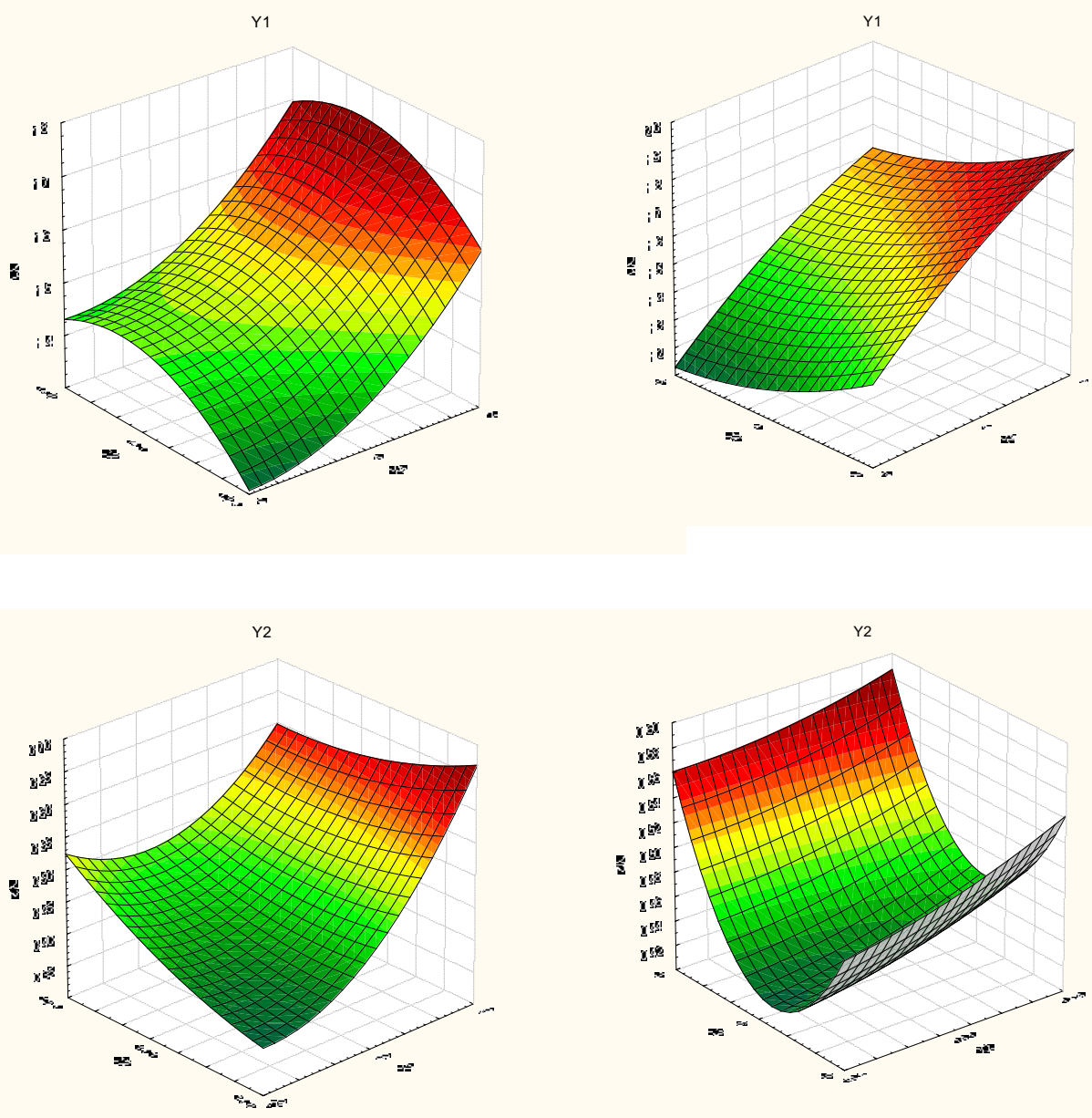

Fig. 2. Response surfaces for grinding module and energy intensity.

Based on the analysis of the above surfaces, rational values of the grinder parameters are determined, at which the grinding modulus is $1.3 \mathrm{~mm}$, the energy consumption is 0.472 $\mathrm{kW} \cdot \mathrm{s} / \mathrm{kg}$, then the circumferential speed of the hammers is $100 \mathrm{~m} / \mathrm{s}$, the moisture content of the material varies from $13.6 \%$ to $14.1 \%$, the diameter of the holes of the separation screen is $5 \mathrm{~mm}$, and the number of rows of hammers will be 4 [11-13].

\section{Conclusion}

Analysis of research materials of existing structural and technological diagrams of fodder preparation lines and technical facilities for stem fodder grinding showed that a promising direction in terms of increasing the efficiency of this process and reducing energy and metal consumption and material costs, the most efficient use of technical facilities for stem fodder grinding, which is based on the principle of supporting grinding by a hammer-segment type working tool. 
The analysis of the obtained dependencies showed that the energy intensity of the process with a decrease in the radius of the drum will decrease along with an increase in quality indicators.

Dependence analysis showed that the speed of movement of material particles directly depends on the diameter of the grinding chamber. The smaller the diameter of the grinding chamber, the thinner the grinding modulus of the material, and the more efficient and better the working process.[14-15]

As a result of the experimental studies carried out on the basis of a priori information analysis and search studies, the following most significant factors were identified: $\mathrm{X}_{1}$ - circumferential speed of hammers $(\omega), \mathrm{m} / \mathrm{s} ; \mathrm{X}_{2}$ - moisture content of material (W), $\% ; \mathrm{X}_{3}$ diameter of holes of separating screen $(d), m m ; X_{4}$ - number of rows of hammers (n).

The criteria for optimizing the grinding process by the hammer-segment type working element are: $\mathrm{Y}_{1}$ - grinding modulus $(\mathrm{M}), \mathrm{mm} ; \mathrm{Y}_{2}$ - energy intensity $\left(\mathrm{N}_{\mathrm{sp}}\right) \mathrm{kW} \mathrm{s} / \mathrm{kg}$.

The results of calculations of economic efficiency of coarse feed grinder with hammersegment type working element show:

- the annual economic effect on the reduced costs from the use of one dispenser is 126450 rubles;

- limit price 963459.1 rub.

\section{References}

1. V.Yu. Frolov, Sel'skij Mekhanizator, 6, 22-23 (2019)

2. M.I. Tumanova, V.Yu. Frolov, D.P.Sysoev, N.Yu. Sarbatova, Research Journal of Pharmaceutical, Biological and Chemical Sciences, 9 (3), 958 (2018)

3. M.I. Tumanova, V.Yu. Frolov, D.P.Sysoev, N.Yu. Sarbatova, Research Journal of Pharmaceutical, Biological and Chemical Sciences, 6 (6), 13440 (2019)

4. V.I. Kuznecov, N.Yu. Morozova, S.P. Farshanev, V.Yu. Frolov, Vestnik NGIEI, 10 (101), 49-61 (2019)

5. G. Parkhomenko, S. Kambulov, A. Olshevskaya, et al., IOP Conf. Ser.: Earth Environ. Sci., 403, 012144 (2019), doi:10.1088/1755-1315/403/1/012144

6. Y. Lachuga, A. Soloviev, A. Matrosov, et al., IOP Conf. Ser.: Earth Environ. Sci., 403, 012055 (2019), doi:10.1088/1755-1315/403/1/012055

7. I. Bozhko, G. Parkhomenko, S. Kambulov, et al., E3S Web Conf., 175, 05025 (2020), https://doi.org/10.1051/e3sconf/202017505025

8. B. Meskhi, V. Bondarenko, I. Efremenko, et al., IOP Conf. Series: Mater. Sci. Eng., 1001, 012100 (2020), doi:10.1088/1757-899X/1001/1/012100

9. Y. Lachuga, B. Akhalaya, Y. Shogenov, et al., IOP Conf. Ser.: Mater. Sci. Eng., 1001, 012121 (2020), doi:10.1088/1757-899X/1001/1/012121

10. V. Pakhomov, T. Maltseva, N. Kulikova, et al., E3S Web Conf., 210, 07003 (2020), https://doi.org/10.1051/e3sconf/202021006012

11. O. Kholodov, M. Kholodova, Z. Kolycheva., et al., IOP Conf. Ser.: Mater. Sci. Eng., 918, 012144 (2020), doi:10.1088/1757-899X/918/1/012144

12. A. Soloviev, A. Matrosov, I. Panfilov, et al., E3S Web Conf., 210, 05017 (2020), https://doi.org/10.1051/e3sconf/202021005017

13. Y. Lachuga, B. Akhalaya, Y. Shogenov, et al., E3S Web Conf., 210, 08016 (2020), https://doi.org/10.1051/e3sconf/202021008016 
14. D. Molochnikov, P. Khalimov, I. Gayaziev, et al., E3S Web Conf., 210, 08006 (2020), https://doi.org/10.1051/e3sconf/202021008006

15. V.V. Ivanov, S.I.Popov, N.S. Dontsov, et al., E3S Web Conf., 210, 01006 (2020), doi.org/10.1051/e3sconf/202021001006 